\title{
Hearing screening program for school going children in India: necessity, justification, and suggested approaches
}

Mohammad Shamim Ansari* (D)

\begin{abstract}
Background: It is estimated that about $15 \%$ of students have transient hearing loss worldwide sufficient enough to interfere with communication, psychosocial relationship, and learning resulting in poor educational achievement and poverty. However, these conditions are reversible through timely detection and effective interventions. India is home to the largest number of school age children with hearing impairment, and majority of them remain undetected and untreated due to the absence of any dedicated hearing screening program. Therefore, this paper attempts to convince all stakeholders for planning and implementing early detection and intervention program for children with hearing impairment in school settings.

Methods: Recent literature estimates that children between the ages 0 and 14 years contribute $25.9 \%$ of the total Indian population. As per the global estimates of the prevalence of hearing impairment, India houses the largest number of school age children with hearing impairment. Many of them either remain out of school or perform poorly in school curriculum.
\end{abstract}

Results: The children in educational programs are readily and easily available for applying hearing screening procedures to detect hearing impairment and instituting audiological and educational remedial measures. But unfortunately, India has not yet envisaged any dedicated early detection and intervention program for school-going children consequently majority of children with hearing impairment undetected and untreated in the classroom.

Conclusion: Hearing impairment is a serious health concern among school age children which can adversely impact on communication, educational achievement, and vocational options. However, screening approaches for early identification in school age children across the world which are simple, effective, and cost-efficient can be considered for countries like India to reverse the ill effects of hearing impairment.

Potential implication: The paper may heighten the awareness among school personnel, educational administrators, and policymakers to consider planning and implementation of early detection and intervention program for children with hearing impairment in school settings.

Keywords: Hearing impairment, Hearing screening, School-going children, Early detection and intervention

*Correspondence: msansari5000@yahoo.com

Department of Audiology, AYJNIHSD (D), K.C. Marg, Bandra (W, Mumbai 400050, India

\section{Background}

Hearing impairment is a serious health concern in countries like India. The hearing impairment isolates an individual from the learning environment that results in breakdown in the linkages for development of speech and language, academic performances, cognitive abilities, and emotional and psychosocial well-being of the child 
as well as family members [1]. Hearing disorder is manifested in many forms and magnitudes and can occur at all life stages. It can be sensorineural, conductive, mixed, central auditory processing, and functional in nature. Hearing loss could vary from mild loss to profound (pure tone average 26 to $91 \mathrm{dBHL}$ and above) degree. It could be either in one ear or both ears [2].

The disorders of the external and middle ear result in conductive hearing loss, which in turn reduces the amount of sound reaching to the inner ear. The disease of cochlea or cochlear nerve results in sensorineural hearing loss. Such people not only receive the attenuated sound energy but also the distorted quality of sound including speech. The disorder of the central auditory system is more subtle and complex. Northern and Down (2002) reported that children with central auditory processing difficulties may have normal hearing on pure tone audiometry. However, they often manifest poor discrimination ability to understand speech in degraded listening environment such as background noise or presence of competing messages $[2,3]$.

Hearing impairment of severe to profound degree at birth or acquired during schooling period affects the child's ability to acquire or develop speech-language skills and scholastic performances to great extent. The children even with a moderate degree of hearing loss may behave like severely deaf in the presence of noise especially in classroom situation and perform poorly on scholastic activities [3]. Hence, the school hearing screening programs are assuming major importance in early detection of hearing loss of varying degrees in school age children. The identification of hearing changes often makes it possible to implement corrective actions and to prevent from further deteriorations.

\section{Magnitude of the problem}

There are about 466 million people who have disabling hearing loss, and 34 million of these are children globally. The disabling hearing loss refers to hearing loss greater than $30 \mathrm{~dB}$ in the better hearing ear in children and about $80 \%$ of people with disabling hearing loss who live in lowand middle-income countries (LMICs) as defined by the World Bank [4]. In LMICs, approximately 7.5 million children (about 6 per 1000 live births) have disabling sensorineural hearing impairment $[5,6]$.

The Census of India (2011) reports that hearing impairment affects about 5.07 million and 1.98 million of the populations with various types of speech problems almost uniformly distributed around the country [7]. Pascolini and Smith reported bilateral severe to profound hearing loss affect more than 10 infants in every 1000 live births in developing countries [8]. Niskar et al. found $14.9 \%$ of children with either low-frequency or high-frequency hearing loss in a hospital-based survey [9]. Norman et al. reported the prevalence of hearing impairment to be $30.9 \%$ in school children (aged $8-14$ years) in the villages of Vadamavanthal, Tamil Nadu [10].

The Census of India (2011) reports that one in every 100 children in the age group 0-6years suffered from some type of disability. 20.42 lakhs ( 2.42 million) children aged 0-6years are disabled and among them, 23\% are having disability in hearing. Furthermore, out of the total disabled ( 7.87 million) in the age group $0-19$ years, $20 \%$ are hearing disabled. The disabled persons are highest (4.62 million) in the age group 10-19 years. The disabled children aged 5-19years who are attending educational institution are found to be only $61 \%$ [11]. According to recent data from the sample registration survey of India (SRS: 2018), the children between the ages of 0 and 14 years made up $25.9 \%$ of the population [12]. Thus, considering the prevalence rate of hearing impairment in this age segment, it can be assumed that the world's largest school age child population with hearing disability reside in India.

These children are easily and readily available in schools for hearing screening and to provide appropriate technological rehabilitation, speech training, and educational facilities for their optimal growth. But these children remained undetected and untreated in the classroom as India has not yet envisaged any dedicated early hearing detection and intervention program. As a result, majority of these children suffer from poor scholastic achievement and socioeconomic insufficiency leading to poor illiteracy and poverty among them. This necessitates the identification of hearing impairment in children and to provide them rehabilitative and educational services ensured in Right to Person with Disabilities Act - 2016 [13] and Right to Education Act - 2009 [14]. Therefore, this paper endeavors to convince all stakeholders by addressing the need, significance, and justification for planning and implementing early detection and intervention program for children in the school setting. It also intends to suggest hearing screening approaches for application.

\section{Hearing screening}

Hearing screening is a rapid, cost-effective, and accurate method designed to picking out those individuals most likely to have a hearing impairment that may interfere with communication or educational development [2]. Hearing screening programs do not assess the deficit but use the pass/fail criteria to group those warranting further evaluation. The goal of a hearing screening is to identify children with hearing loss in order to allow for further diagnosis and intervention [15]. It should be 
relatively simple to perform, require minimal preparation, and be cost-efficient $[2,16]$. Hearing screening methods for school-going children are simple, appropriate, and efficient for the identification of hearing loss.

\section{Need of screening in school going children}

Hearing deficits of severe to profound degree in children can interfere with oral communication, language and psycho-social development, and classroom learning. The child who is hard of hearing or deaf receives the remedial services at an early age, he/she is more likely to achieve optimal speech, language, and social skill acquisition [17]. However, children with a lesser degree of hearing loss, i.e., mild to moderate hearing problems, are forgotten children in schools, as teachers are rarely aware of the presence of hearing impairment in child in classrooms. These children if remained undetected may be at a disadvantage educationally, emotionally, and socially and may behave like severely hearing-impaired children $[18,19]$. This necessitates an early detection of mild-moderate hearing loss to provide effective medical treatment and to compensate for the loss through amplification.

Children with mild to moderate degrees of losses often go undetected by family members and teachers and may lead to the child being labeled as a daydreamer, slow learner, inattentive and disobedient, etc. [19]. They often have peer relationship issues and suffer from low self-esteem [20, 21]. However, these conditions are preventable and ameliorable through early detection and intervention and specialized educational services. These students may be provided with amplification devices, auditory training, speech conservation, and speech-language therapy, etc. In addition, guidance and counseling for teachers, parents, and hard of hearing can be facilitated [22].

\section{Significance of screening school going children}

Hearing is one of the essential doorways of learning. The loss of hearing sensitivity of any degree compromises effective learning as all formal learning and educational activities in school environments are mediated through the sense of hearing. Hearing screening for school going children offers the following advantages [22, 23]:

- Good number of school children of various ages are easily accessible and readily available for hearing screening in the school environment.

- School hearing screening program offers the opportunity to screen children who have progressive hearing loss or inflected the hearing loss later or could not be previously screened or identified.

Hearing screening can be conducted in a relatively short period of time with more ease:
- Hearing screening strategies are far less expensive than comparable services performed in another sector of the health care system.

- School hearing screening program provides continuing prospect to observe, evaluate, and examine potential areas of concern.

\section{Approaches for school hearing screening}

It is estimated that up to $15 \%$ of students exhibit at least a transient hearing loss at some time during their school years sufficient enough to interfere with education [22]. Thus, educationally significant hearing loss (ESHL) is the target disorder for school age hearing screening that could potentially interfere with a learner's academic performance. ESHL is specified as a threshold $>20 \mathrm{~dB} \mathrm{HL}$ at 1,2 , or $4 \mathrm{kHz}$ in either ear [23]. ESHL may include sensorineural, conductive, or mixed hearing loss and may also include transient conductive losses. Hearing screening programs should be initiated for pre-school or school age children to favor equal educational opportunities who suffer from communication disorders [24].

A systematic screening program with correct equipment, trained personnel, and adequate follow-up services will allow children with ESHL to be accurately diagnosed and managed to provide them with learning opportunities. Thus, ongoing review of hearing and speech ageappropriate milestones, risk factors, and routine hearing screening is critical to detect the hearing impairment. The commonly employed strategies are pure tone audiometric screening, acoustic immittance screening, highrisk register criteria, and Behavioral Checklist \& Health History Questionnaire, etc.

\section{Pure tone audiometric screening}

The most accepted method of screening hearing in school-going children is pure tone audiometry along with immittance audiometry to identify the children with middle ear disease and to supplement the information obtained in pure tone hearing screening $[23,25]$. Pure tone audiometry is conducted at $1000 \mathrm{~Hz}, 2000 \mathrm{~Hz}$, and $4000 \mathrm{~Hz}$; when an immittance procedure is not used, $500 \mathrm{~Hz}$ may also be considered for screening. Each ear of students is screened at $20 \mathrm{dBHL}$ in a controlled environment with appropriate instruction to raise the hand each time the tone is presented at a specific frequency.

The pure tone audiometry is the most frequently used audiological tool for deciding medical, surgical, or rehabilitative strategies and monitoring benefit with interventions. The recommended follow-up pure tone audiometry is as follows:

Every 3 months - during the first year of diagnosis.

Every 6 months - during preschool years.

Every year - while in school. 


\section{Acoustic immittance measurement}

Acoustic immittance incorporates two procedures, tympanometry, and acoustic reflex. Tympanometry measures change in acoustic impedance or admittance at the eardrum. The air pressure changes usually from +200 dapa to -300 dapa are artificially induced into a hermitically sealed ear canal in the presence of tone frequency of $226 \mathrm{~Hz}$ at $85 \mathrm{dBHL}$ [25]. Acoustic reflex screening procedure measures a change in acoustic impedance or admittance at the lateral surface of the eardrum with the delivery of tone intensity of $105 \mathrm{dBHL}$ at $1000 \mathrm{~Hz}$ [26]. The presence of "A" type tympanogram and acoustic reflex to tone intensity $105 \mathrm{dBHL}$ at $1000 \mathrm{~Hz}$ is considered as normal integrity of the auditory system for sound transmission to the inner ear and beyond.

\section{Behavioral checklist}

Observing the behaviors of the child as certain peculiar behaviors or traits may suggest the presence of hearing loss in the child [27]. These traits can be of great help or source in suspecting hearing health of school-going children. The commonly cited behaviors include the following:

- Peculiar listening behaviors such as cupping the ear, cocking the head, leaning forward to listen, turning the head to localize sound with the better ear, effortful and stressful facial expression

- Lack of attention

- Attention-seeking behaviors

- Frequent request for repetition of what has been said

- Poor at dictation

- Irrelevant answers to the question

- Frequent mistakes in carrying out the oral instruction

- Speech defects

- Restlessness and listening fatigue

- Poor scholastic performances

If any of these behavior or combinations of behaviors are present in the child, he/she can be suspected of some problem in hearing. The family members can play a major role in suspecting hearing loss, as they are in best position to interact with the child and observe the auditory behavior and other related traits. The major concern is to create awareness among family members and teachers to identify such children, so that suspected children could be referred and can be given comprehensive audiological tests and appropriate intervention thereupon.

Children with unilateral or lesser degree of hearing loss do not find much difficulty in receiving conversational speech. However, the children may find difficulty in sustaining attention in the classroom especially when the background noise is at a high level. In such situations, the hearing-impaired child may exhibit some specific patterns of behavior, and these patterns may become the family's concern, not the hearing. The family members' concern about the child's inattentiveness, poor at studies, or repeated ear infections to physician or family doctor should be doubted as a potential case for hearing impairment.

\section{High-risk registry of hearing loss}

High risk students of hearing loss [18, 20, 21, 28, 29] in schools are those who:

- Repeat a grade.

- Are enrolled in special/ exceptional educational program.

- Are new to the school system (integrated child).

- Failed the threshold test during the previous year.

- Child was absent during the previously scheduled hearing screening.

- Have speech and language problems and obvious problems in communication.

- Have medical problems commonly associated with hearing impairment.

- Are involved in coursework that places them at risk for noise exposure like, woodworking, band and auto mechanic, etc.

- Previously documented hearing impairment.

- Having a family history of deafness.

- Long-term absentee from school because of major illness.

- Recurrent middle ear infection.

If these high-risk children are made known to parents, teachers, and other school personals, it will alert them regarding the child's auditory behaviors which may facilitate early identification and subsequent referral for audiological assessment. Furthermore, physicians, pediatricians, and otolaryngologists may play a major role in identifying and subsequent referral of children with highrisk registers, syndromic and medical condition, and medical treatment that may cause hearing loss, so that the hearing specialist may conduct the suitable test to ascertain audiological profile [30].

It is advisable to perform an audiogram on all such children, but even in absence of an audiometer, the wealth of information by means of $512 \mathrm{~Hz}$ simple tuning fork test and speech test can be obtained by asking simple questions softly and asking the child to repeat words or phrases that a normal child should be able to hear. If a child repeats soft-spoken words properly, it may indicate near-normal hearing, but it must always bear in mind that many times children hear and yet do not respond. If it is assumed that the responses are reliable, and the 
child fails to hear soft voices/sounds. The physician then should use a $512-\mathrm{Hz}$ tuning fork to find out whether the impairment is conductive or sensorineural and to apply effective treatment. If the physician is unable to suggest proper treatment, it is his obligation to refer the child to an otologist or hearing clinic for required medical, surgical, or rehabilitative services.

\section{Scenario in the country}

India is home to the highest number of children with hearing impairment in the world. 1.57 million children are hearing disabled in the educable age group $0-19$ years. The number of disabled children is highest in the age group 10-19years (4.62 million). 4.01 million $(61 \%)$ out of 6.58 million disabled children aged 5-19years are attending educational institutions, and only $60 \%$ of those who attend school complete class 10 . As the per India Social Development Report - 2016, there are about 75 million children of primary school age who are out of school, among them "one-third are children with disabilities." Further, only $2 \%$ of the PWDs were enrolled in any vocational course [31].

269.8 million or $21.9 \%$ of the Indian population are poor whereas poverty in the disabled population is about $30-40 \%$ [32]. One in every two disabled non-workers is dependent on their respective families. These numbers are a reminder that India is still a long way from meeting goal 4 of the United Nation's Sustainable Development Goals (UNSDGs) of ensuring "inclusive and equitable quality education" and "lifelong learning opportunities for all" by 2030 [33].

The reasons may be found in the report of the 76th round of the National Sample Survey 2019 which states $76.4 \%$ of persons with disabilities have not received any kind of aid and appliances from the government, and only $28.8 \%$ have a disability certificate from a competent authority essential for availing subsidized hearing aid and cochlear implant and other facilities. About $89.8 \%$ of children with disabilities do not have access or could not receive pre-school intervention services [34]. Thus, the lack of timely detection of hearing impairment, inability to purchase or obtain assistive technologies and learning materials, and inaccessible intervention services probably are factors for the high rate of literacy and poverty in the disabled population.

Illiteracy and poverty among the disabled have inexorable concerns, as illiterate and poor are more susceptible to ill health, exploitation, and human rights abuses [35]. Poverty has been the cause of persistent illiteracy, poor health, and many preventable diseases that have the potential to cause hearing impairment. Since literacy and health are essential indicators of the quality of a country's human capital, these are probably the pertinent reasons why India still ranks low in most of the global human capital indices [36]. If we intend to eradicate the illiteracy and poverty among the disabled population, we must detect hearing loss at the earliest and provide effective remedial measures.

\section{Challenges in early detection of hearing impairment}

Hearing impairment is a matter of serious concern as it has wider implications on health and education on a huge number of children in schools. The school-going children with hearing impairment are spread and living over 3288 million $\mathrm{km}^{2}$ of land, in 718 districts across 28 states and 9 union territories in our country. Moreover, there is scarcity of manpower for the early diagnosis and intervention for hearing impairment [12]. As per WHO (2009), ENT specialists and audiologists in India are about 8000 and 2500 in numbers, respectively. The audiologist versus population ratio was found to be $1: 500,000$ and the ratio of speech therapists or special educator to the deaf population is 1:200 [37]. There are around 5000 speech pathologist and audiologist (SLPAs) in India. Further, there is also a misdistribution of personnel with more hearing health care professionals who are working in urban areas than in rural and suburb regions [38]. In addition to these problems, the facilities for dissemination of information to create awareness in the public, policymakers, administrators, and academics are also inadequate.

\section{Opportunities for early detection of hearing impairment}

India has a very impressive infrastructure for disseminating primary health care and rehabilitation services. There are nine national institutes which are engaged in human resources development, delivery of rehabilitation services to the persons with disabilities, dissemination of information and documentation, and research and development in the field of disability. There are 19 composite regional centers that have been established for persons with disabilities in various states to provide both preventive and promotional aspects of rehabilitation like education, health, employment and vocational training, research, and manpower development. The comprehensive services and capacity building to the persons with disabilities are augmented by 262 district disability rehabilitation center across the country [39].

There are 3907 ICDS projects covering nearly $70 \%$ of the country's community development blocks and 260 urban slum pockets. Rural health services are facilitated by $1,31,900$ health subcenters, each for every $5000 \mathrm{popu}-$ lation in plain and 3000 population in tribal areas. There are 21,693 primary health centers for 30,000 populations in plain and 20,000 populations in tribal/hilly areas. 
There are 2385 upgraded community health center to cover 80,000 to 1.20 -lakh populations [39]. Each of these centers has gramsevikas, anganwadi workers, multipurpose workers, health workers, viklangbandhus, nurses, etc., and many other governmental and non-governmental organizations equipped with men and materials to take up early detection programs.

The Artificial Limbs Manufacturing Corporation (ALIMCO) is a Central Public Sector for the manufacture and supply/distribution of Assistive Devices for Persons with Disabilities. It has provided about 42 lakhs of assistive device to PwDs across the country. The National Handicapped Finance and Development Corporation (NHFDC) provides financial loan up to 25.0 lakh at 5-8\% interest rate for setting up income-generating activities. Educational loan is also available for pursuing higher education, i.e., graduation, post-graduation professional courses. The maximum amount of loan is Rs.10.0 lakh within India and Rs.20.0 lakh for courses abroad. The rate of interest is $4 \%$ per annum (rebate of $0.5 \%$ on interest is allowed to women beneficiaries) [39].

\section{Conclusions}

The curricular and extracurricular educational and academic activities in school environments are mediated through the sense of hearing. Hence, hearing impairment of any degree compromises effective learning in the school environment resulting in poor academic performance in children with hearing impairment that may have future ramifications on employment socioeconomic status [29]. However, identification of hearing impairment of pre-school or school age children and providing appropriate intervention can help to enhance academic performance and improve the employability and quality of life.

Therefore, hearing screening programs should be initiated to support equal educational and learning opportunities for children who suffer from communication disorders due to hearing impairment in school programs. A methodical and planned hearing screening program will allow to accurately diagnose the educationally significant hearing loss and to provide appropriate intervention in form of amplification devices, speech-language therapy, and other educational remedial measures in order to ensure equitable and inclusive learning opportunities enshrined in the RTE Act - 2009 and RPWD-Act 2016 and echoed in the Draft National Education Policy (NEP) 2019. The NEP has recommended setting up DisabilityInclusive Fund to build the nation's capacity by providing equitable quality and inclusive education for all [40].

A methodical screening program will allow children with ESHL to be accurately diagnosed and managed to provide them with equal learning opportunities. This has been ensured in the RTE Act - 2009, RPWD-Act 2016 and echoed by the Draft National Education Policy 2019 which recommends setting up Disability-Inclusive Fund to build the nation's capacity to provide quality and equitable education for all [40].

Hearing impairment can be identified by simple, reliable, and cost-effective methods such as family/hearing health questionnaire, risk registers, pure tone audiometry, and acoustic immittance measurement which are efficient and cost-effective. The children with suspected hearing impairment may be referred for diagnosis and intervention. In spite India has a gigantic population of children with hearing impairment in the educable group and these children are readily available for detection of hearing impairment, but unfortunately, India does not have any dedicated program for early identification and intervention in school settings as yet.

Furthermore, planning and implementation of a hearing screening program in school will heighten the awareness about hearing care and hearing health among school administrators, teachers, parents, and students. This will promote hearing health care values in them. Thus, there is an urgent need for planning and implementation of early identification and intervention program for hearing in school settings for children in particular and other school personnel in general.

\section{Acknowledgements}

I submit my sincere thanks to all individuals with hearing impairment and deafness who influenced my thoughts for writing the article.

\section{Author's contributions}

Conceptualization, preparation writing, and proofreading were done by the single author. The author(s) read and approved the final manuscript.

Funding

No external funding—-self-financed.

Availability of data and materials Not applicable.

\section{Declarations}

Ethics approval and consent to participate

Ethical approval is not required. The materials referred have been duly acknowledged.

Consent for publication

Not applicable.

Competing interests

The author has no conflict of interest to declare.

Received: 13 August 2021 Accepted: 22 October 2021

Published online: 16 November 2021

References

1. Yoshinaga-Itano C, Sedey AL, Coulter DK, Mehl AL (1998) Language of earlyand later-identified children with hearing loss. Pediatrics. 102(5):1161-1171

2. Northern JL, Downs MP. Hearing in children. Lippincott Williams \& Wilkins; 2002 
3. Crandell C, Smaldino J (2000) Room acoustics for listeners with normalhearing and hearing impairment. Audiology treatment:601-637

4. World Health Organization. Addressing the rising prevalence of hearing loss. 2018. Available from: https://www.who.int/pbd/deafness/estimates/ en

5. Morton CC, Nance WE (2006) Newborn hearing screening-a silent revolution. N Engl J Med 354(20):2151-2164

6. UNICEF (2013) The state of the world's children 2013: children with disabilities. UNICEF, New York

7. Chandramouli C (2011) General R. census of India 2011. Provisional population totals. Government of India, New Delhi, pp 409-413

8. Pascolini D, Smith A (2009) Hearing impairment in 2008: a compilation of available epidemiological studies. Int J Audiol 48(7):473-485

9. Niskar AS, Kieszak SM, Holmes A, Esteban E, Rubin C, Brody DJ (1998) Prevalence of hearing loss among children 6 to 19 years of age: the third National Health and nutrition examination survey. Jama. 279(14):1071-1075

10. Norman P, Chandran M, Dhandapani T (2016) Prevalence of hearing impairment in school children (aged 8-14 years) in the villages of Vadamavanthal, Tamil Nadu, India. Int J Community Med Public Health 3(12):3369-3373

11. Verma D, Dash P, Bhaskar S, Pal RP, Jain K, Srivastava RP, Hansraj N (2016) Disabled persons in India: a statistical profile 2016. Ministry of Statistics and Programme Implementation, Government of India

12. Office of the Registrar General \& Census Commissioner, Sample registration survey of India (SRS: 2018). Ministry of Home Affairs, Government of India. Available from https://censusindia.gov.in/vitalstatistics/SRS Report 2018/9.Chap 2-Population_Composition-2018.pdf

13. Ministry of Law and Justice, Government of India. The rights of persons with disabilities Act (2016) Gazette of India (extra-ordinary). Government of India, New Delhi, p 2016

14. RTE Act. The Right of Children to Free and Compulsory Education Act 2009. Constitution of India article 21- a, Ministry of law and Justice, government of India, New Delhi The Gazette of India 2009

15. Hayes D \& Northern, JL. Comprehensive assessment of infants with hearing loss (cited in); Infant and Hearing (ed.), Singular Publishing Group Inc., 1996; 265-270

16. Yoshinaga-Itano C (2003) From screening to early identification and intervention: discovering predictors to successful outcomes for children with significant hearing loss. J Deaf Stud Deaf Educ 8(1):11-30

17. Bess FH, Dodd-Murphy J, Parker RA (1998) Children with minimal sensorineural hearing loss: prevalence, educational performance, and functional status. Ear Hear 19(5):339-354

18. Mackenzie I, Smith A (2009) Deafness - the neglected and hidden disability. Annals of Tropical Medicine \& Parasitology 103(7):565-571

19. Bess FH (1999) School-aged children with minimal sensorineural hearing loss. The Hearing Journal 52(5):10-12

20. McKay S, Gravel JS, Tharpe AM (2008) Amplification considerations for children with minimal or mild bilateral hearing loss and unilateral hearing loss. Trends in amplification 12(1):43-54

21. American Academy of Audiology (2011) Clinical practice guidelines: childhood hearing screening. American Academy of Audiology, pp 1-62

22. American Speech-Language-Hearing Association. Guidelines for manual pure-tone threshold audiometry. ASHA, 2005
23. Skarzynski H, Piotrowska A (2012) Screening for pre-school and schoolage hearing problems: European consensus statement. Int J Pediatr Otorhinolaryngol 76(1):120-121

24. Epstein S, Reilly JS (1989) Sensorineural hearing loss. Pediatr Clin N Am 36(6):1501-1520

25. Roeser R. Screening for hearing loss and middle ear disorders in the schools. In R. Roeser \& M. Downs (Eds.), Auditory disorders in schoolchildren (3rd ed., pp. 76-100). 1995; New York: Thieme Medical Publishers

26. Johnson D, Seaton J (2011) Educational Audiology Handbook (2nd Ed). Cengage Learning, Clifton NJ

27. Tharpe A, Bess F (1991) Identification and management of children with minimal hearing loss. Int J Pediatr Otorhinolaryngol 21:41-50

28. Joint Committee on Infant Hearing. Year 2007 Position statement: principles and guidelines for early hearing detection and intervention programs. Pediatrics, 2007; 120(4), 898-921

29. Moeller MP, Tomblin JB, Yoshinaga-Itano C, Connor CM, Jerger S (2007) Current state of knowledge: language and literacy of children with hearing impairment. Ear Hear 28(6):740-753

30. Deshpande A. Disability and disadvantage in India. India social development report- 2016; 17-48

31. Seema Gaur \& N Srinivasa Rao. Poverty measurement in India: a status update-2020. Ministry of Rural Development Working Paper No. 1/2020, $1-22$

32. United Nations, Sustainable Development Goals Report. 2019. Goal 4 of the United Nation's Sustainable Development Goals (UNSDGs) 2030. https://unstats.un.org/sdgs/report/2019/The-Sustainable-DevelopmentGoals-Report-2019.pdf

33. Persons with disabilities in India. National Sample Survey- 2019: NSS report no. 583: -NSS $76^{\text {th }}$ round (July - December 2018). Ministry of Statistics \& Programme Implementation, Government of India, 2019

34. Bokova I, Bush L (2012) Literacy is key to unlocking the cycle of poverty. Houston Chronicle

35. World Bank Group. World development report 2019: the changing nature of work. World Bank, 2019

36. World Health Organization. Newborn and infant hearing screening: current issues and guiding principles for action. WHO Press, 2009. Geneva. Available fromhttps://apps.who.int/iris/bitstream/handle/10665/339288/ 9789241599496-eng.pdf

37. Kumari Jagriti. Times News Network Correspondent. Times of India. 24.11.2020. Available from: https://timesofindia.indiatimes.com/home/ education/news/india-needs-trained-audiology-and-speech-languagePathologists/articleshow/79384098.cms?

38. The Department of Empowerment of Persons with Disabilities. District Disability Rehabilitation, Government of India Annual Report (2020-21)

39. Status of disability in India-2000. Kundu C L (Ed.) New Delhi: Rehabilitation Council of India, 2000

40. Ministry of Human Resource Development - MHRD, Government of India (2019). Draft National Education Policy 2019. 145

\section{Publisher's Note}

Springer Nature remains neutral with regard to jurisdictional claims in published maps and institutional affiliations. 